\title{
Environomic design of vehicle energy systems for optimal mobility service
}

\author{
Zlatina Dimitrova ${ }^{a, b}$, François Maréchal $^{c}$ \\ ${ }^{a}$ PSA Peugeot Citroën, Vélizy, France, zlatina.dimitrova@mpsa.com \\ ${ }^{b}$ Ecole Polytechnique Fédérale de Lausanne, Lausanne, Switzerland, zlatina.dimitrova@epfl.ch \\ ${ }^{c}$ Ecole Polytechnique Fédérale de Lausanne, Lausanne, Switzerland, francois.machechal@epfl.ch
}

\begin{abstract}
:
The main design criteria for the modern sustainable development of vehicle powertrains are the high energy efficiency of the conversion system, the competitive cost and the lowest possible environmental impacts.

An innovative decision making methodology, using multi-objective optimization technics is currently under development.

The idea is to obtain a population of possible design solutions corresponding to the most efficient energy system definition. These solutions meet technical, economic and environmental optimality.

This article applies the methodology on an electric vehicle, in order to define the powertrain configuration of the vehicle, to estimate the cost of the equipment and to show the environmental impacts of the technical choices of the powertrain configurations in a life cycle perspective.

A physical model of the electric vehicle is made and coupled with a cost model for the vehicle and LCA technics are used for the environmental assessment.

After multi-objective optimizations with thermo-economic and environmental objectives, the solutions obtained from the Pareto frontiers curve are analysed. Conclusions about the environomic design of the vehicle for optimal mobility service are made.

The greenhouse gas emissions are calculated from a well-to-wheel perspective for different countries of use of the electric vehicle, according to their respective electricity production mixes.
\end{abstract}

\section{Key words:}

Electric vehicle, Energy conversion technologies, Economic models, Environmental models, Multi-objective optimization.

\section{Nomenclature}

Environomic design

$L C A$

CAFE

$P S A R \& D$

$T-t-W$

GNG

$S I$

ICE

$P_{\text {eff }}$

$m_{\text {fuel }}$

$L H V$

$N E D C$

EMOO

$M O O$

MILP

MINLP

$\mathrm{NiMH}$

GWP 100y
Environmental, economic and efficiency design

Life Cycle Assessment

Corporate Average Fuel Economy

PSA Research and Development

Tank to Wheel

Compressed natural gas

Spark ignition

Internal combustion engine

Effective power in [ $k W]$

Fuel flow rate $[\mathrm{kg} / \mathrm{s}]$

Low heating value $[\mathrm{kJ} / \mathrm{kg}]$

New European Drive Cycle

Evolutionary Multi Objective Optimization

Multi Objective Optimization

Mixed Integer Linear Programming

Mixed Integer Non Linear Programming

Nickel Metal hydride

Global Warming Potential for 100 years in [ $\mathrm{kg}$ CO2 equivalent] 


\section{Introduction}

With the increasing trend of mobility of the human population, vehicles have to face the problem of primary energy resources scarcity. The vehicles need higher efficiency and better adaptation to the alternative energy sources.

The need to improve the efficiency of the vehicle energy system motivates the search for innovative solutions during the design process.

This paper presents a systematic methodology for the optimal design and configuration of a vehicle powertrain system, considering environomic criteria. Multi-objective optimization technics are used in combination with economic and LCA models for optimal electric vehicle powertrain design.

A worldwide convergence for low $\mathrm{CO} 2$ emission vehicles is observed. The automotive industry needs to deploy massively, in the future (Figure 1), affordable technical solutions for highly energy efficient vehicles. Electric vehicles are seen as a way to reduce the tank to wheel $\mathrm{CO} 2$ emissions for the vehicle fleets.

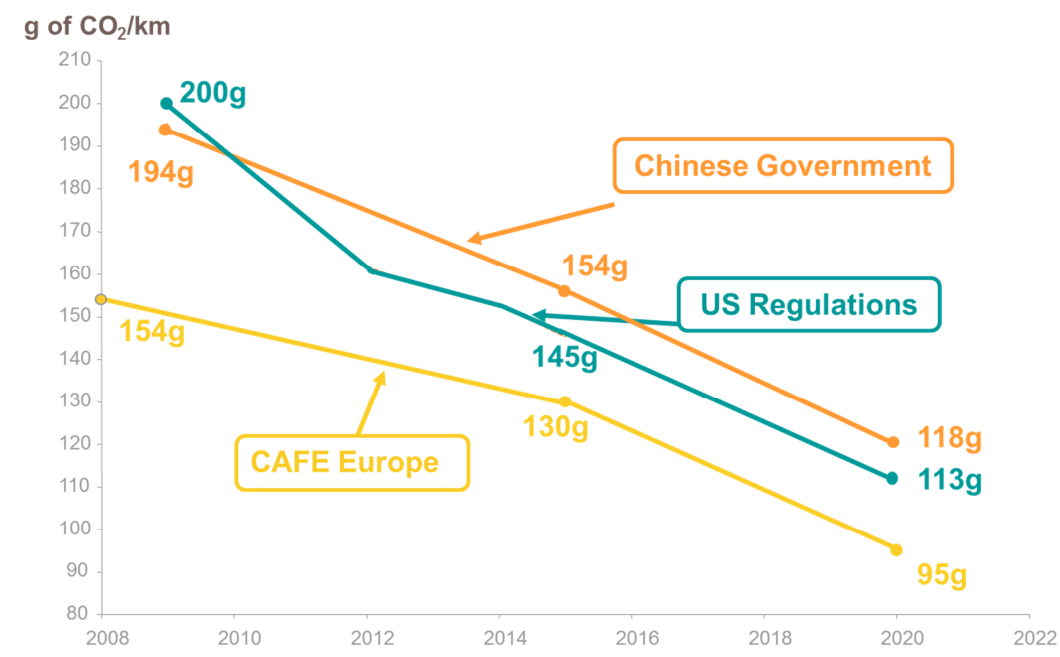

Figure 1 : future requirements for efficient vehicles $* T-t-W$ CO2 emissions [1]

Important aspects of the work are the design and the operating strategies of the powertrain system [2], and the reduction of the energy requirement for mobility [2], [3].

According to the efficiency and the cost, the thermo-economic approach has been applied to the design of optimal hybrid electric powertrains in [4], [5] and [6]. Guzzella works also with the efficiency/cost balance of the systems with different simulation and optimization approaches. In this work a holistic decision making methodology for electric vehicle powertrain design is adapted. 
Finally, the environmental performances of vehicles are more and more relevant to the automotive customer acceptance. The Life Cycle Assessment (LCA) seems to be one of the most suitable methodologies for the assessment of a large range of environmental impacts of the product [7].

Many previous studies discussed the environmental impacts of the vehicles [8], [9], but very few used a life cycle perspective integrating the LCA in the conceptual design of the vehicle energy system.

This study takes into account the environmental impacts (greenhouse gases, ODP, acidification, eutrophication) in the earlier development stage.

Therefore, this paper aims to combine the thermo-economic optimization methodology with the integration of the LCA in the conceptual design of vehicle energy system. The resulting method is illustrated by an application case study of the electric vehicle.

\subsection{Conversion systems and efficiency:}

The electric vehicle has electrochemical on-board energy storage devices - high voltage batteries. The batteries have the lowest energy density in comparison with hydrocarbon fuels, but the electric "tank-to-vehicle" conversion systems have a very high conversion efficiency [3]. Table 1 illustrates this dependency. Thermal convertors have a low conversion efficiency and use fuels with a higher energy density than electric "tank-to-vehicle" conversion systems. Thus the electric vehicle is characterized with a high powertrain mass, because of the low energy density of the high voltage batteries.

Table 1 : Required energy mass (in $\mathrm{kg}$ ) for on-board storage, for $50 \mathrm{MJ} / 100 \mathrm{~km}$ vehicle autonomy

\begin{tabular}{lccccc}
\hline Fuels & Gasoline & Diesel & CNG & Electricity & \\
\hline Vehicle autonomy [3] & 50 & 50 & 50 & 50 & $\mathrm{MJ} / 100 \mathrm{~km}$ \\
Convertors & SI ICE & Diesel ICE & CNG ICE & EM & \\
Efficiency of the convertors & & & & & \\
(average) [3] & 0,17 & 0,2 & 0,16 & 0,9 & $(-)$ \\
Energy before conversion (A.1) & 294 & 250 & 13 & 56 & $\mathrm{MJ} / 100 \mathrm{~km}$ \\
Storage efficiency [3] & 1 & 1 & 313 & 0,8 & $(-)$ \\
Energy in the tank (A.2) & 294 & 250 & & $69 *$ & $\mathrm{MJ} / 100 \mathrm{~km}$ \\
Density of the energy vector [3] & 42,7 & 42,5 & 49,1 & $0,648^{*}$ & $\mathrm{MJ} / \mathrm{kg}$ \\
Mass kg/100 km (A.3) & 7 & 6 & 6 & 107 & $\mathrm{~kg} / 100 \mathrm{~km}$ \\
\hline
\end{tabular}

*Electricity in the battery

From the state of the art, we have to notice that the achieved energy density is approximately $40 \mathrm{Wh} / \mathrm{kg}$ for lead-acid, 30-55 Wh/kg for Ni-metal hydrides, $100 \mathrm{Wh} / \mathrm{kg}$ for Li-Ion, 110 $\mathrm{Wh} / \mathrm{kg}$ for molten sodium batteries [3].

\subsection{Integration of LCA in thermo-economic models used for the optimal conceptual design of energy conversion systems.}

This methodology is applied to the assessment of the impacts and the optimization of emergent technologies such as the production of fuels or electricity from biomass or integrated systems for electricity production.

Some studies on the use of LCA in process design have already been conducted mainly in chemical process systems. The key idea is to optimize a system, considering a cumulated environmental impact and minimizing the operating costs. 
Some recent studies [11],[12],[13],[14] presented a systematic approach for integrating LCA in process systems design using multi-objective optimization in the field of combined fuels and electricity production from renewable sources (biomass, geothermal). The major advantage is that it allows considering simultaneously the influence of the process design and its integration on the thermodynamic, economic and environmental life-cycle performance at the early stages of conceptual design [14].

In particular the aims of this paper are to apply the LCA- based multi-objective optimization in the early design stage and to design an energy conversion system for an electric vehicle, taking into account the cost, the efficiency and the usage of the natural resources, thus minimizing the generated life- cycle impacts.

\section{Methodology - Computational framework}

\subsection{Optimization methodology}

A multi-objective optimization model with an evolutionary algorithm has been developed. An electric vehicle dynamic model gives the mechanical flows of the vehicle. The energy integration and optimization structure is the slave structure, linked by the state variables with the dynamic and economic models.

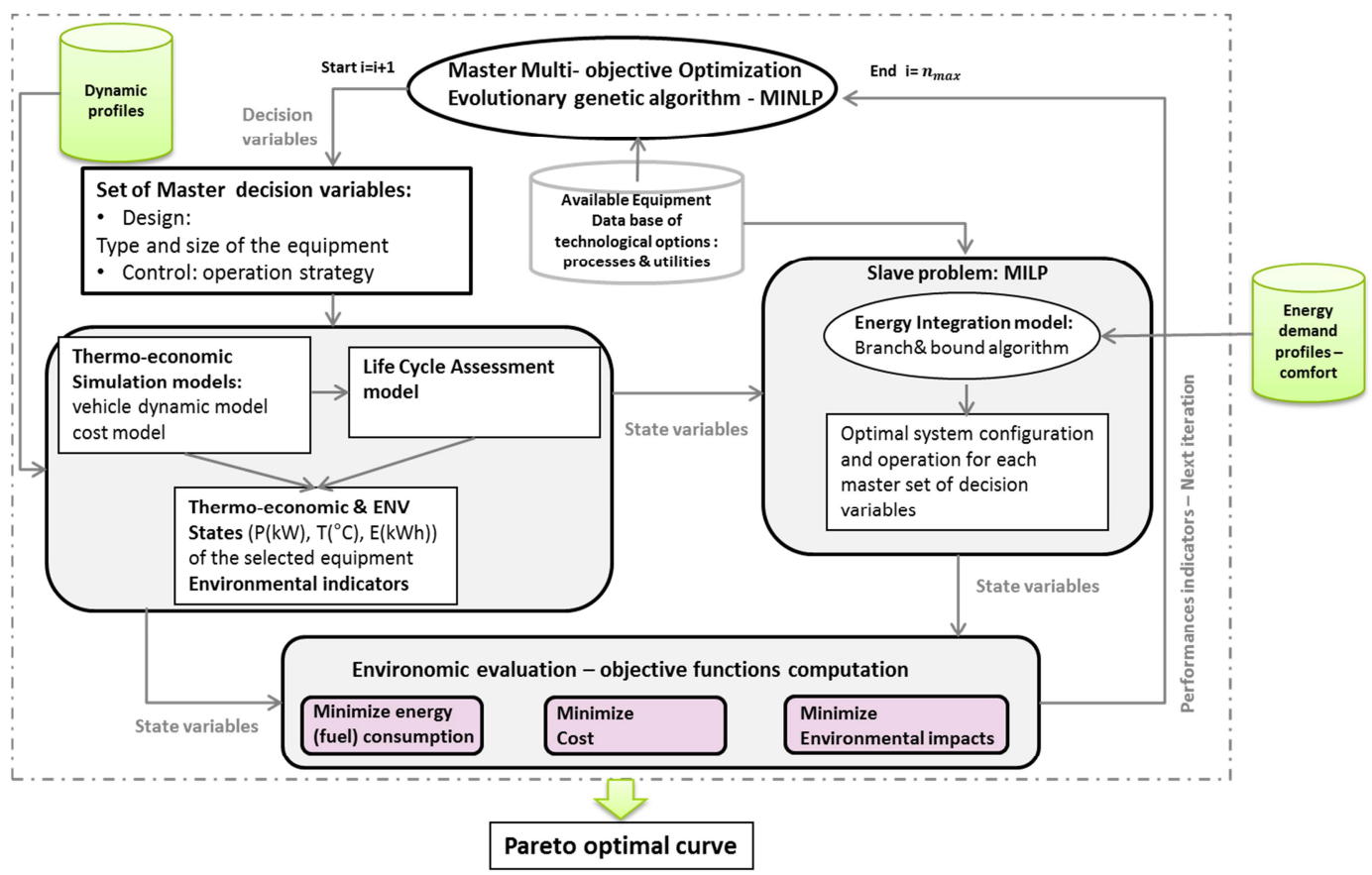

Figure 2: Structure for multi-objective optimization

The developed model (Figure 2) is a mixed integer non- linear problem (MINLP). It is solved by a decomposition method, using a master-slave algorithm in which decision variables can be grouped in master or slave sets [15].

The master set of decision variables includes the type and the size of the equipment. These variables are used to define a superstructure for the vehicle energy system [16]. The energy technologies database is presented as a list of available equipment, and the characterizing equipment tags are inputs for the master optimization problem. The master optimization is solved by an evolutionary genetic algorithm - EMOO. 
The superstructure receives sets of master decision variables and objective functions. Then the efficiency and the economic states are calculated using simulation models of the vehicle dynamic behavior. The cost and the LCA models are also executed. The list of fuels or electricity, operating cycles (time, speed profiles) and ambient temperatures are requested for the optimization. The output is a proposition of equipment. The selected superstructure is in the master level and the results of the optimization are used in the post-processing phase to calculate the objective functions of the master problem [16]. The objective functions are environomic (environmental, economic and efficiency) indicators. After the specified iterations by the user, the optimal solutions converged on the Pareto frontier curve.

\subsection{Dynamic vehicle model:}

The vehicle simulation tool is SIMULINK $®$. The vehicle model is based on mechanical and electric flows. For the moment the thermal behaviour of the vehicle for comfort or mobility is not taken into account. The conversion system is composed of an electric motor and gearbox. An energy recovery model, for the deceleration phase is developed and coupled to the reversible conversions in the motor or generator mode of the electric machine. The energy storage devices are the battery and a parallel structure of supercapacitors. The level of the models is quasi-static. The vehicle is able to follow dynamic profiles coming from a library of normalized vehicle drive cycles. The vehicle is defined with a physical model (Table A.1) and the NEDC cycle is used for the dynamic calculations.

\subsection{Economic Model:}

The cost of the vehicle is computed for each run as a function of the size and efficiency of the energy convertors and energy storage devices. The cost of the equipment comes from the literature and is related to the size of the components. The cost of the electric motor includes the cost of the power unit. The battery cost is sensitive to the battery type and the energy storage capability of the material. The nominal cost represents the vehicle shell cost, without the powertrain components. This linear correlation (3), (Table 2) takes into account the price of the parts and the manufacturing cost of the vehicle shell and includes the margin of the carmaker. The correlation is built using the Peugeot Citroën official customer prices for different vehicle classes and illustrates the link between the increasing cost and the increasing size and weight of the vehicle. The car shell is defined as a completely equipped vehicle (body, interior equipment, wheels), except the powertrain. The powertrain for the electric vehicle is composed of the electric machine, gear box, super capacitors and high voltage battery with power electronics.

For each calculation, a new vehicle mass is calculated and updated with the mass of the defined powertrain.

Table 2: equations for the economic model

\begin{tabular}{lcc}
\hline Components & Costs [€] \\
\hline Convertors & $30[€ \mathrm{~kW}] *$ power_el.motor $[\mathrm{kW}]$ & $(1)$ \\
Electric motor [4] & $600 *[€ \mathrm{kWh}] * q_{\text {bat }}^{0.2477 * \log (\text { bat } \text { specifmass }}($ bat_type $\left.)+0.5126\right)$ & $(2)$ \\
\hline $\begin{array}{l}\text { Storage system } \\
\text { Battery [4] }\end{array}$ & $17.3 *$ car_shell_mass $[\mathrm{kg}]-3905.4[€]$ & $(3)$ \\
\hline Body & & \\
Nominal cost (car shell) & $0.14269[€[T C / \mathrm{kWh}]$
\end{tabular}


A simplified vehicle objective cost function is constructed, composed of the vehicle powertrain cost and the vehicle body cost during the production phase.

The total mobility cost is composed of the investment and operating costs.

The cost equations are presented in Appendix B.

\subsection{Environmental model:}

The life cycle of a product, a system or a service has usually three distinct successive phases: the production phase, the use phase and the end-of-life phase. The vehicle unitary processes and flow diagram are defined in Figure 3.

The functional unit for the LCA is the total distance driven throughout vehicle's lifetime $150000 \mathrm{~km}[17]$.

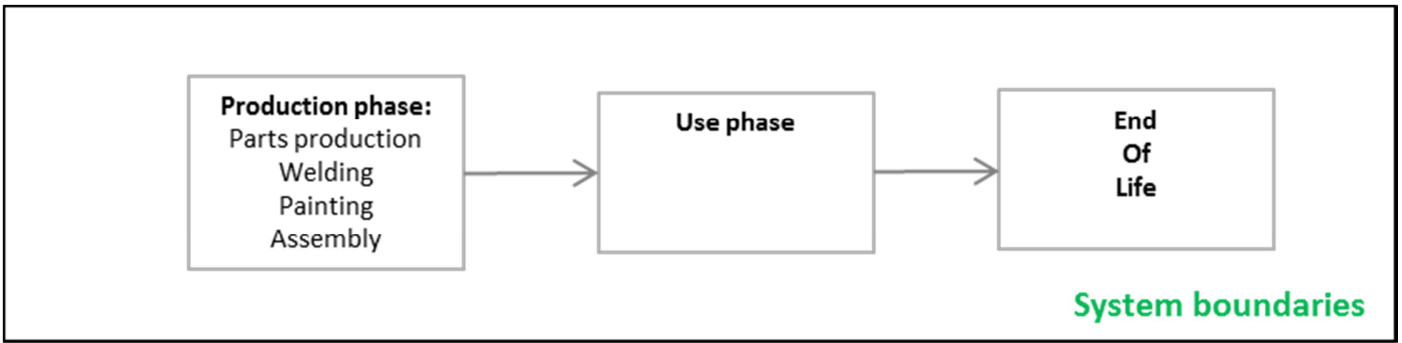

Figure 3: vehicle unitary processes flow chart - system definition

The inventory in the production phase is composed of:

- the mass material balance for each part of the vehicle sub-system

- the corresponding manufacturing process in the Eco Invent ${ }^{\circledR}$ database

- the data about the manufacturing processes in the vehicle production plant (welding, painting, assembly)

The unitary processes and the raw materials for the production of the parts come from the Eco Invent ${ }^{\circledR}$ database. The vehicle is divided into seven substructures, which allows to distinguish the powertrain: electric machine, low voltage battery, high voltage battery, power unit, thermal engine and gearbox, vehicle body (car shell).

The use phase corresponds to the energy consumption of the vehicle. The inventory for the corresponding "energy carrier" production comes from the Eco Invent ${ }^{\circledR}$ database (Table 3). The end-of-life phase is represented by the average car disposal process, issued by the Eco Invent ${ }^{\circledR}$ database. 
Table 3: Energy vectors database (data of 2005)

\begin{tabular}{lcc}
\hline Energy vector & Eco Invent process number & Description \\
\hline Electricity & Nuclear (France) \#700 & $77 \%$ Nuclear, $12 \%$ hydro \\
Hydraulic (Norway) \# 712 & $87 \%$ Hydro \\
Coal + other renewable (Germany) \#706 & $44 \%$ coal, 25\% nuclear \\
Hydro + Nuclear (Switzerland) \#697 & Coal (Poland) \#715 & $31 \%$ hydro, 44\% nuclear \\
& C8\% coal
\end{tabular}

This study refers to the four main impact categories used in the automotive industry: GWP 100 years, acidification potential, eutrophication potential and ozone depletion (Table C.1). The CML01_short impact method is used in the master superstructure for MOO calculations. This method has just four impact categories and this allows for an acceptable computing time, which is important for the main validation of the environmental objective optimization.

\section{Multi-Objective Optimization of the vehicle energy system}

\subsection{Problem definition:}

In this paper a MOO is performed for electric cars. The environmental impacts are chosen as optimization functions, in addition to the cost and the efficiency. The environomic optimization is applied and discussed for an electric vehicle. Based on the Pareto curves drawn by the MOO, optimal vehicle configurations of the cars are discussed and decided.

The environmental impact categories (GWP, eutrophication, acidification and ODP), coming from the LCA model as performance indicators in the superstructure, are used as objective functions.

Table 4: Decisions variables for design - multi-objective optimization problem

\begin{tabular}{lll}
\hline Electric propulsion system component & Range & Unit \\
\hline Electric machine & {$[15-50]$} & $\mathrm{kW}$ \\
Battery Ni-MH, $30 \mathrm{Wh} / \mathrm{kg}$ & {$[10-50]$} & $\mathrm{kWh}$ \\
Number of super capacitors & {$[0-5]$} & {$[-]$} \\
in a parallel structure & & $\mathrm{kW}$ \\
Max Power of supercapacitors & 87,5 & \\
\hline
\end{tabular}

The electric propulsion components are defined as decision variables for the design of the system.

The optimization function is defined as:

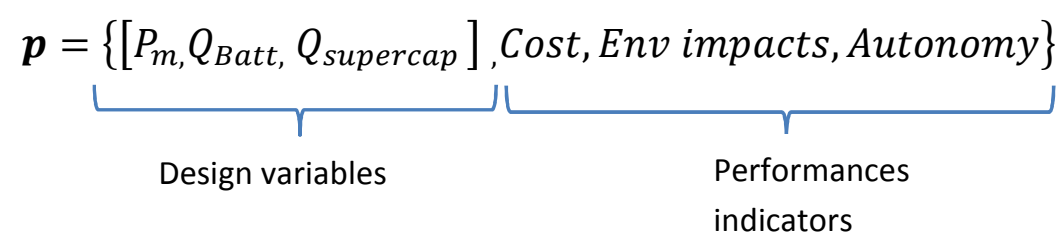

The autonomy is defined as the distance in kilometers covered by the vehicle in one full charge of the high voltage battery (A.4).

The optimization function maximizes the autonomy and minimizies the environmental impacts and the cost. According to the number of objective functions one distinguishes 2D and 3D optimization.

2D MOO : 
- maximize autonomy

- minimize environmental impacts

3D MOO:

- maximize the autonomy

- minimize the environmental impacts

- minimize the cost

\subsection{MOO results for environomic vehicle energy systems - 2D MOO}

The solutions of two objective optimization functions converged on a Pareto frontier optimal curve (Figure 4). They are obtained by simulation of the superstructure model described in figure 2.This Pareto optimal curve represents the trade-off between the functions: the autonomy and the environmental categories (Acidification, GWP, Eutrophication and ODP).
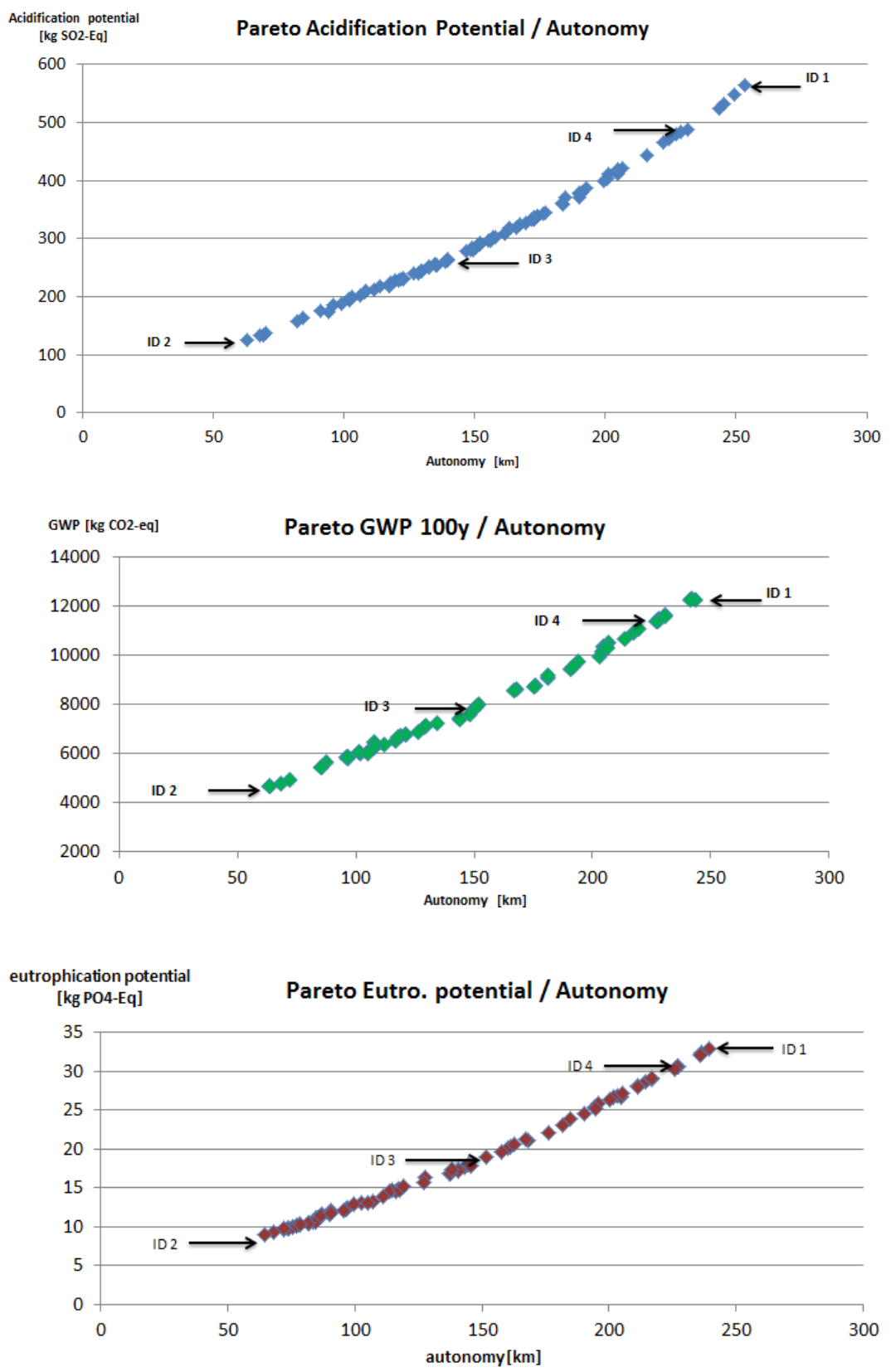


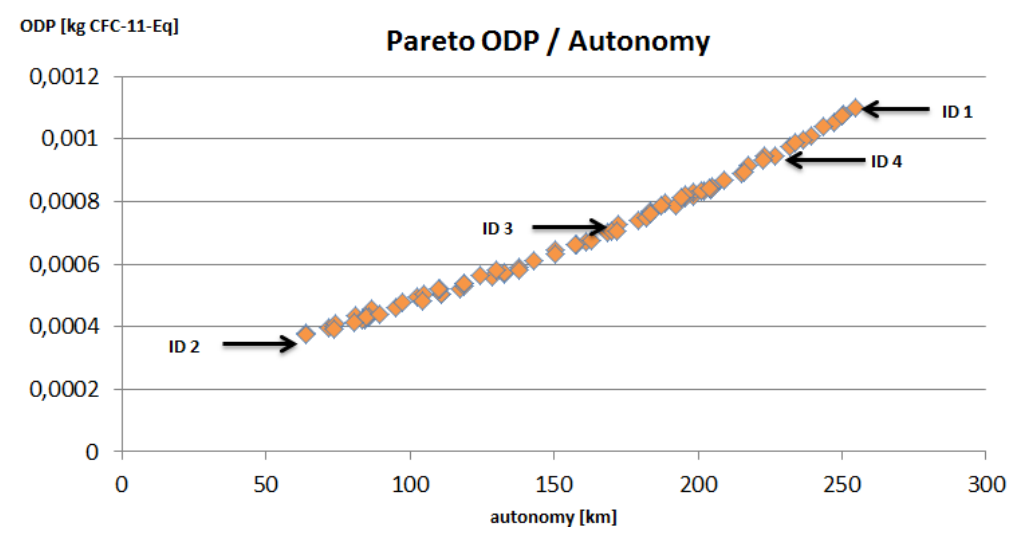

Figure 4: Pareto frontier curves for 2D MOO - Environmental impact and autonomy

On the NED Cycle a correlation is visible for all graphs - all environmental categories are increasing with increasing autonomy. The reason is that, for electric vehicles, the autonomy is related to the battery capacity and respectively its size. The environmental impacts show the importance of the production phase of the vehicle and the impact of the battery production on the global LCA.

In the case of electric vehicles, the environmental impacts in the use phase are related to the electricity consumption and production mixes. The MOO is done in case of vehicle usage in the case where the vehicle is used in France. The French electriciy mix is in majority nuclearbased $(77 \%)$ (Table 3).

Table 5 gives examples of orders of magnitude for the vehicle design with minimized environmental impacts.

Table 5: Optimal vehicle design solutions for $2 \mathrm{D} M O O$

\begin{tabular}{|c|c|c|c|c|c|}
\hline GWP opti & ID 2 & ID 3 & ID 4 & MINI E & ID 1 \\
\hline Vehicle mass [kg] & 730 & 1015 & 1305 & 1465 & 1375 \\
\hline Energy of the battery & & & & & \\
\hline [kWh] & 10 & 24.8 & 42 & 30 & 46.4 \\
\hline $\begin{array}{l}\text { Power max of the } \\
\text { supercapacitor [W] }\end{array}$ & 52500 & 35000 & 52500 & & 87500 \\
\hline Electricity consumption & & & & & \\
\hline$[\mathrm{kWh} / 100 \mathrm{~km}]$ & 8.5 & 9.8 & 11.4 & 13 & 11.8 \\
\hline Autonomy [km] & 64 & 150 & 227 & 228 & 242 \\
\hline Vehicle cost [€] & 14880 & 25082 & 35804 & 32000 & 38938 \\
\hline Use cost [€] on FU & 1820 & 2104 & 2434 & 2782 & 2516 \\
\hline
\end{tabular}

The correlations of the environmental impact with the autonomy can be approximated by quadratic functions, with very small quadratic coefficents (Table 6). In the selected autonomy range from $50 \mathrm{~km}$ to $250 \mathrm{~km}$, the correlation functions are almost linear.

Table 6: environmental impact vs autonomy correlations for the use phase in France and for the autonomy range of [50-250] km

\begin{tabular}{lccc}
\hline Correlation use phase France & \multicolumn{1}{c}{ Equation } & Error \\
\hline Acidification $=\mathrm{f}($ autonomy) & $y=0.0045 x^{2}+0.8181 x+62.512$ & $R^{2}=0.9991$ & $(5)$ \\
GWP 100y $=\mathrm{f}($ autonomy) & $y=0.0701 x^{2}+20.127 x+3213$ & $R^{2}=0.9983$ & $(6)$ \\
Eutrophication $=\mathrm{f}$ (autonomy) & $y=0.0002 x^{2}+0.0615 x+4.0441$ & $R^{2}=0.9993$ & $(7)$
\end{tabular}


The comparison of the vehicle design is done for the same optimal autonomy points and for different environmental impact categories (Table 7 and Table 8).

The vehicle design solution - Point 4 is representive of the electric vehicle in the small $\mathrm{B}$ segment, with urban and peri - urban usage.

Point 2 is compared to point 4 . The solutions for point 2 correspond to light and small urban vehicles, adapted for a daily commuting distance of $30 \mathrm{~km}$. The design solutions are optimal for each impact category - Acidification, GWP, Eutrophication and ODP (Table 7, Table 8).

Table 7: MOO results for different environmental functions - Acidification, GWP, Eutrophication, ODP for autonomy of $227 \mathrm{~km}$

\begin{tabular}{|c|c|c|c|c|}
\hline ID 4 & Mini Acidification & Mini GWP & Mini Eutrophication & Mini ODP \\
\hline Vehicle mass $[\mathrm{kg}]$ & 1305 & 1305 & 1303 & 1300 \\
\hline Energy of battery [kWh] & 42 & 42 & 42 & 42 \\
\hline Power max supercap [W] & 87500 & 17500 & 17500 & 52500 \\
\hline Electricity consumption [kWh] & 11.4 & 11.4 & 11.4 & 11.3 \\
\hline Autonomy $[\mathrm{km}]$ & 227 & 227 & 227 & 227 \\
\hline $\mathrm{GWP}\left[\mathrm{kg} \mathrm{CO} \mathrm{CO}_{2} \mathrm{eq}\right]$ & 11472 & 11319 & 11349 & 11405 \\
\hline Acidification $\left[\mathrm{kq} \mathrm{SO}_{2}\right.$ eq] & 478.9 & & & \\
\hline Eutrophication $\left[\mathrm{kg} \mathrm{PO}_{4} \mathrm{eq}\right]$ & & & 30.58 & \\
\hline ODP $[\mathrm{kg}$ CFC- 11 eq] & & & & $9.46 .10^{-4}$ \\
\hline
\end{tabular}

Table 8: MOO results for different environmental functions - Acidification, GWP, Eutrophication, ODP for autonomy of $64 \mathrm{~km}$

\begin{tabular}{lcccc}
\hline ID 2 & Mini Acidification & Mini GWP & Mini Eutrophication & Mini ODP \\
\hline Vehicle mass [kg] & 783 & 730 & 755 & 782 \\
Energy of battery [kWh] & 10 & 10 & 10 & 10 \\
Power max supercap [W] & 70000 & 52500 & 87500 & 87500 \\
Electricity consumption $[\mathrm{kWh}]$ & 8.6 & 8.5 & 8.6 & 8.7 \\
Autonomy [km] & 63.04 & 64 & 64 & 64 \\
$\mathrm{GWP}\left[\mathrm{kg} \mathrm{CO}_{2}\right.$ eq] & 4894 & 4657 & 4811 & 4918 \\
Acidification [kq SO${ }_{2}$ eq] & 125.3 & & 8.89 & $3.8 .10^{-4}$ \\
Eutrophication $\left[\mathrm{kg} \mathrm{PO}_{4}\right.$ eq] & & & & \\
ODP [kg CFC-11 eq] & & &
\end{tabular}

For the points ID 4 and ID 2 (Table 7, Table 8) the selected optimal vehicle design is the same for all optimal points of each category. Minimizing the GWP 100 years category leads to minimizing the other 3 impact categories. To conclude, the environmental optimization can be simplified to one impact category - with GWP as the objective to minimize.

On the NED Cycle the use of supercapacitors doesn't influence the autonomy of the vehicle. The supercapacitors are efficient by delivering high power in a small laps of time, and the battery is used for energy storage. The supercapacitors are activated during the acceleration and deceleration phases. The autonomy depends mostly on the quantity of energy available on board - i.e. from the battery. 


\subsection{MOO results for environomic vehicle energy systems - 3D MOO}

There is a trade-off between the cost and the autonomy. The cost seems to have the same variation as the environmental impact: when the autonomy increases, both the cost and the environmental impacts increase, and vice-versa. It is interesting to perform a MOO with three objectives, including the cost. The objectives are:

- maximize the autonomy $[\mathrm{km}]$

- minimize the GWP [kg CO2-eq]

- minimize the cost [€]

The Pareto curve is displayed in Figure 5. The Pareto is obtained by running the superstructure model described in fugure 2.

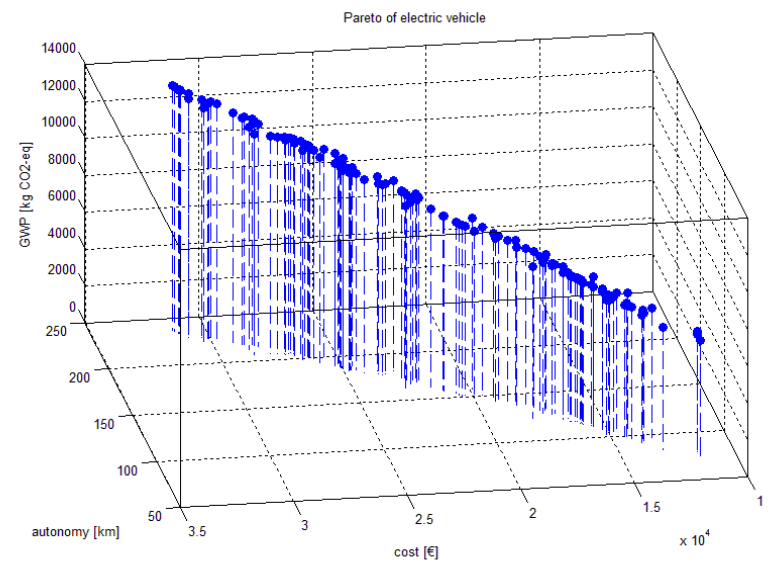

Figure 5: 3D MOO Pareto frontier curve-electric vehicle

Figure A.1 shows the correlation between the autonomy, the cost and the battery energy capacity. The major impact of the cost comes from the battery size, proportional to the battery energy. The coefficient of proportionality between the cost and the energy in the battery is $600 € \mathrm{kWh}$.

To visualize more clearly the dependency between the cost and the GWP, the Pareto curve is plotted in 2D, in the cost-GWP plane (Figure 6).

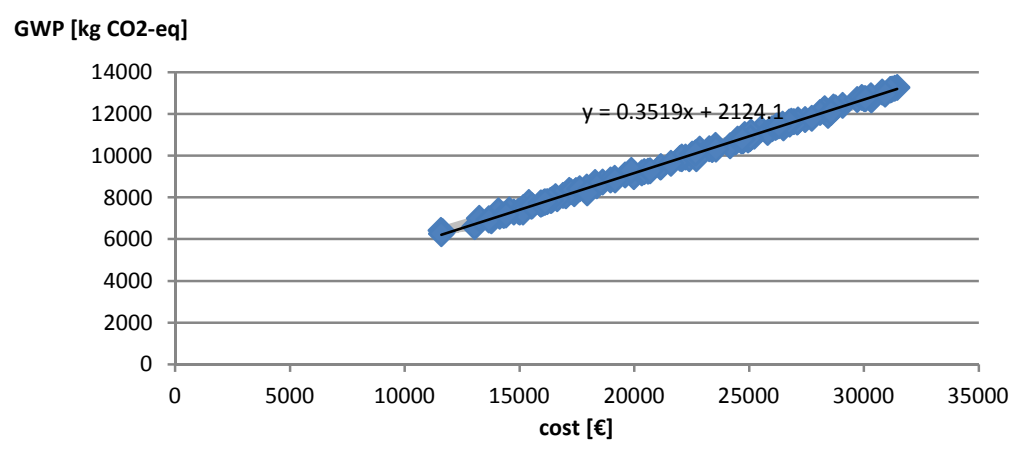

Figure: 6 GWP vs cost Pareto Curve 
The curve is almost a line. Using a linear interpolation, the expression of the dependency between the cost and GWP is:

$G W P=0.3519 * \operatorname{Cos} t+2124.1$

It is important that the slope of the linear model in (9) is positive. It enables to consider the cost or the GWP as the second objective for the MOO, the first objective being the autonomy to maximize. Furthermore one can reduce the dimension of the optimization problem from 3 to 2. Thanks to the fact that the slope in (9) is positive, the optimum of the cost is reached when the optimum of the GWP is reached. Therefore, this 3D optimization (Table 9) should lead to the same optimal configuration found in the 2D optimization (Table 7, Table 8).

Table 9: 3D MOO optimal solutions and cost structure

\begin{tabular}{lcc}
\hline & ID 2 & ID 4 \\
\hline Vehicle mass [kg] & 730 & 1305 \\
Energy of the battery [kWh] & 10 & 42 \\
Power max of supercapacitor [W] & 52500 & 52500 \\
Power el engine [kW] & 30 & 45 \\
Electric consumption [kWh/100km] & 8.5 & 11.4 \\
Autonomy [km] & $\mathbf{6 4}$ & $\mathbf{2 2 7}$ \\
Cost powertrain [€] $\quad$ Cost battery [€] $\quad$ 7950 & $\mathbf{2 7 6 0 0}$ \\
$\quad$ Cost el. machine [€] & 6000 & 25200 \\
$\quad$ Cost supercaps [€] & 900 & 1350 \\
CO2 Bonus [€] & 1050 & 1050 \\
Total investment for customer for powertrain [€] & $\mathbf{- 7 0 0 0}$ & $\mathbf{- 7 0 0 0}$ \\
Cost car shell [€] & $\mathbf{9 5 0}$ & $\mathbf{2 0 6 0 0}$ \\
Total investment cost for customer for vehicle [€] & 8723 & 18671 \\
Total operating cost on FU [€] & $\mathbf{9 6 7 3 , 6}$ & $\mathbf{3 9 2 7 1 , 1}$ \\
Total cost of mobility [€] & $\mathbf{1 7 8 5}$ & $\mathbf{2 3 9 4}$ \\
\hline All costs in & $\mathbf{1 1 4 5 9}$ & $\mathbf{4 1 6 6 5}$ \\
\hline
\end{tabular}

All costs in this table are computed using equations 1 to 3 of Table 2

The optimal solutions are detailed for two points with a characteristic autonomy:

- urban car adapted to commuting mobility (ID 2)

- car with normal autonomy for electric propulsion (ID 4).

The autonomy is related to the battery's energy capacity. The cost structure is shown in Figure 7.

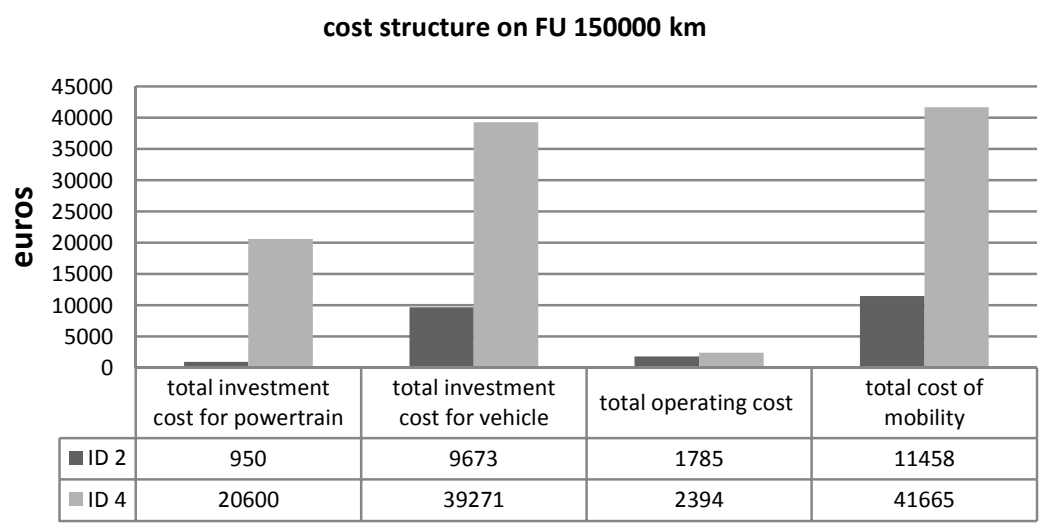

Figure 7: cost structure for the optimal solutions

The powertrain cost is related to the size of the powertrain components - power of the electric machine and the energy capacity of the battery. The high voltage NiMH battery, with specific energy of $30 \mathrm{Wh} / \mathrm{kg}$, represents the biggest impact on the powertrain cost. 
On the other hand the cost of the car shell is linearly related to the mass of the vehicle (3). Thus when increasing the mass of the car shell by a factor of 2 , the cost of the car shell increases by 2 . The vehicle in ID4 represents a higher vehicle class, which is suited for high way and urban use. This vehicle has more interior equipment which contributes to the higher car shell price.

This linear relation takes into account the prices of braking systems, and materials used to make and equip the vehicle. Bigger vehicles with higher mass need braking systems, suspensions, gear-box with higher performances and more vehicle equipment.

When increasing the autonomy, the customer investment cost for the powertrain increases despite the environmental bonus delivered by the government. The customer investment cost of the powertrain for ID 4 is $20600 €$

The customer investment cost for small urban vehicles (ID 2) is very interesting - around $10000 €$, this is equivalent to the investment for urban vehicles with a conventional thermal powertrain.

When increasing the autonomy, the vehicle mass and the size of the other equipment are also increasing. Globally one has four times more investment cost for around four times more autonomy.

The operating cost is related to the electricity consumption of the vehicle and to the price of electricity during the vehicle use phase and depends on the place of use. The calculation here is done with the hypothesis that the vehicle is driven in France with an electricity price of 0.14 $€ \mathrm{kWh}$.

Because of the high conversion efficiency of the electric powertrain and the price of the electricity, the operating cost of electric vehicles, based on the functional unit of $150000 \mathrm{~km}$, is very competitive (Table 9) in comparison with vehicles with a conventional thermal powertrain.

The investment cost contributes very strongly to the total mobility cost.

The life cycle model is used to calculate the environmental impacts for the life cycle of the vehicle and especially the influence of the electricity production mix in the use phase.

The LCA is done for the energy database in Table 3 and ID4. The results are shown in Figure 8.

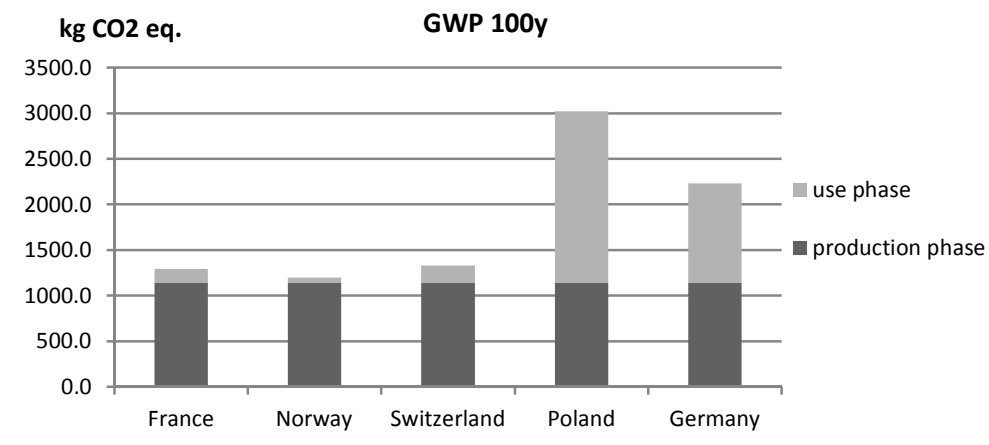

Figure 8: GWP results for an electric car during the use phase in different countries.

In the powertrain production phase, the high voltage battery represents the major environmental impact - around 60\% (Figure C.1).

The materials with the biggest impact on the GWP are the materials extracted for the NiMH battery production. The most important impact comes from the steel and the aluminum for the body production and the plastics used in the interior equipment. For the body construction, these are the materials with the largest mass impact on the total body. The total cotribution of the production phase of the vehicle is around $10000 \mathrm{~kg} \mathrm{CO} 2 \mathrm{eq}$.

The vehicle and the powertrain components are considered as being produced in France. 
The production phase is also the biggest contributor for the other categories - Acidification, ODP and Eutrophication (Figure 9).

acidification
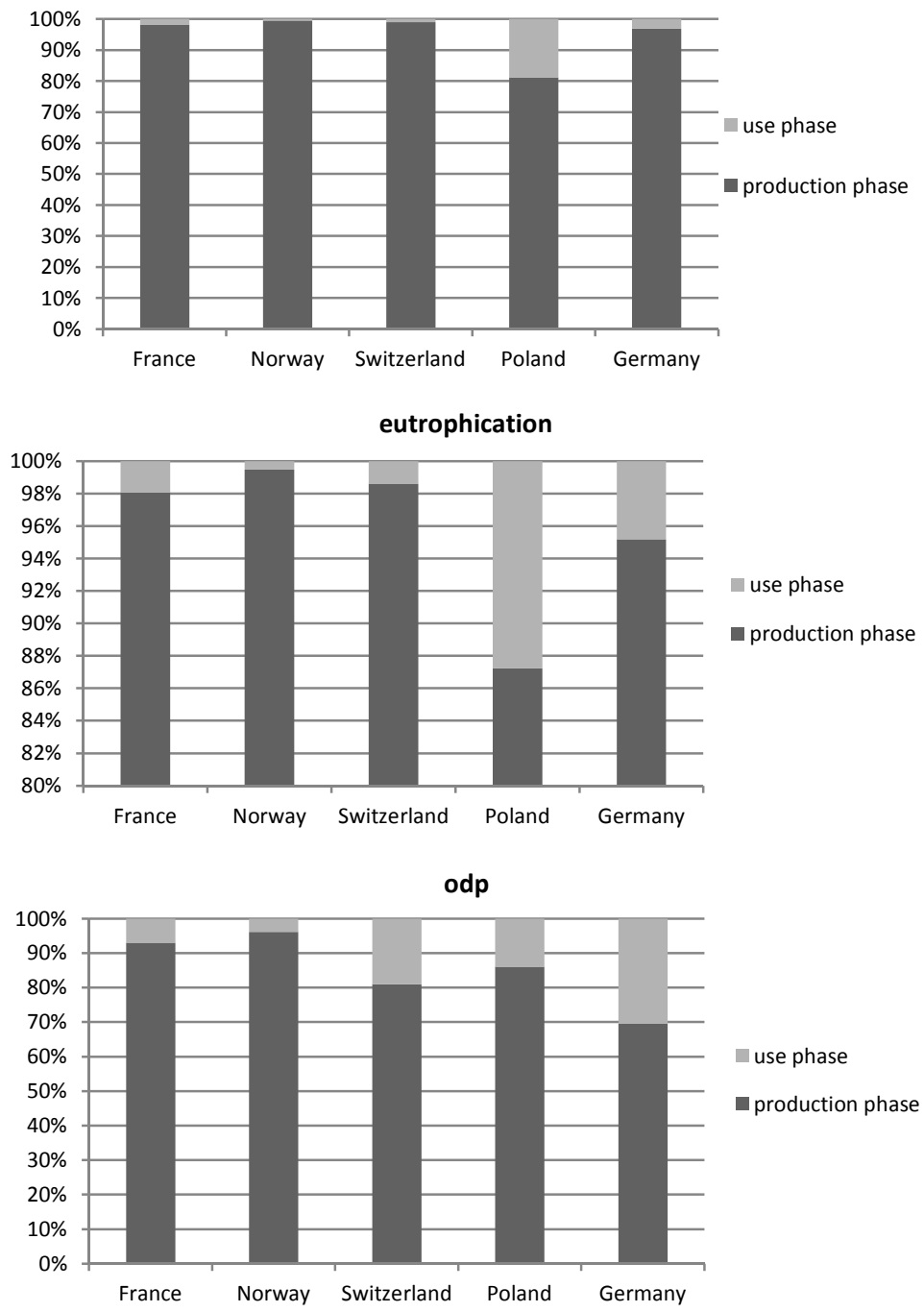

Figure 9: electricity mix and vehicle life cycle influence on the categories Acidification, Eutrophication ODP

The electricity mix has the biggest impact on the use phase. According to the mix composition (Table 3), the GWP can increase more than twice during the use phase (case of Poland - Figure 8) or can represent $10 \%$ of the production phase GWP (case of FranceFigure 8). The use phase GWP can be even lower (less than 10\%) in the case of a mix with dominant renewable energy - for example in Norway.

In this study we took the hypothesis that the battery of the vehicle is recycled and has a second life for other devices. For this reason the end-of-life is approximated to the end-of-life process of a conventional vehicle.

\section{Conclusion:}

This paper describes the combination of the efficiency-economic 2D MOO with the integration of environmental impact minimization in the earlier stages of the conceptual design of electric vehicle energy systems. 3D multi-objective optimization is applied to the 
environomic design of electric vehicle powertrains. It consists of using environmental impacts, cost and autonomy as optimization objectives.

The main conclusion from the 2D optimization, with environmental and autonomy objectives, is that the vehicle design is the same for all optimal impact categories. The environmental optimization can be simplified to one impact category - with GWP as the objective to minimize.

The 3D optimization Pareto shows a linear correlation between the cost and the GWP with positive slope. This illustrates that the optimal solution of the cost function is reached when the optimal solution of the GWP function is reached. The optimization problem can be reduced from 3 to 2 dimensions. The 3D optimization leads to the same powertrain design configurations for the targeted autonomies (ID $2=64 \mathrm{~km}$ and ID $4=227 \mathrm{~km}$ ).

The cost structure for these two solutions is discussed. The battery represents the biggest impact on the powertrain cost - between $75 \%$ and $90 \%$, depending on the autonomy. When increasing the autonomy, the customer investment cost for the powertrain increases because of the battery cost and despite the environmental bonus delivered by the government. The electric vehicle is an adapted solution for urban mobility with around $60 \mathrm{~km}$ of commuting. The very low operating cost of the electric vehicle $(0.00119 € / \mathrm{km}$ for design ID 2) presents major advantages in comparison to the equivalent thermal vehicle.

The governmental bonus for very low T-t-W CO2 emissions of $7000 €$ (applied in France), can help to achieve customer acceptance for the higher investment cost of the electric vehicle. For urban vehicles with around $60 \mathrm{~km}$ of autonomy, the investment cost is equivalent to the customer investment for conventional vehicles - around $1000 €$

The environmental impacts of the electric vehicle during the use phase are related directly to the place of use and the electricity mix of the country. GWP during the use phase can be very low (between 5\% and 15\%) of the total GWP impact, for low CO2 electricity mixes (Norway, France and Switzerland), or can double (Germany) or quasi triple (Poland) because of the high coal percentage used for electricity production. In the production phase of the electric vehicle, the high voltage battery is the main contributor for all the impact categories.

An interesting perspective could be to perform new multi-objective optimization, based on functional unit of $1 \mathrm{~km}$ and two objective functions - minimizing the cost and minimizing the electricity consumption per kilometer. This will help to choose the most efficient powertrain equipment per $\mathrm{km}$ and so the autonomy of the vehicle (based on one full charge) should increase.

\section{Acknowledgments}

I would like to thank Professor François Maréchal for the technical support and his creativity force by leading the ENVIES research project.

I further gratefully acknowledge the daily support of Dr. Tomasz Krysinski and the advice of Dr. Erwann Samson. I highly appreciate the financial support of the PSA R\&D division.

\section{Appendix A:}

$$
\text { Energy_before_conversion }=\frac{\text { Vehicle_autonomy }}{\text { convertors_efficiency }}
$$


Energy_in_the_tan $k=\frac{\text { Energy_before_conversion }}{\text { storage_efficiency }}$

Mass $=\frac{\text { Energy_in_the_tan } k}{\text { Density_of_the_energy_vector }}$

Autonomy_ $[\mathrm{km}]=\frac{\text { total_battery_energy_[kWh]}}{\text { energy_consuption_per_km[ }\left[\frac{\mathrm{kWh}}{\mathrm{km}}\right]}$

Table A.1: vehicle characteristics for the Simulink model

\begin{tabular}{lc}
\hline Characteristics & Symbols and Values \\
\hline Gravity & $\mathrm{g}=9,81\left[\mathrm{~m} / \mathrm{s}^{2}\right]$ \\
Air Density & $\rho_{\text {air }}=1,2[\mathrm{~kg} / \mathrm{m} 3]$ \\
Bearing coefficient & $\mu=0,002[-]$ \\
Rolling coefficient & $\mathrm{fr}=0.01[-]$ \\
& \\
Wind velocity & $\mathrm{v}_{\text {wind }}=0[\mathrm{~m} / \mathrm{s}]$ \\
Slope & $\mathrm{p}=0[\%]$ \\
Aerodynamic coefficient & $\mathrm{Scx}=0,58\left[\mathrm{~m}^{2}\right]$ \\
Vehicle mass & $1420[\mathrm{~kg}]$ \\
Diameter bore & $\mathrm{d}=0,0215[\mathrm{~m}]$ \\
Diameter wheel & $\mathrm{D}=0,52[\mathrm{~m}]$ \\
\hline
\end{tabular}
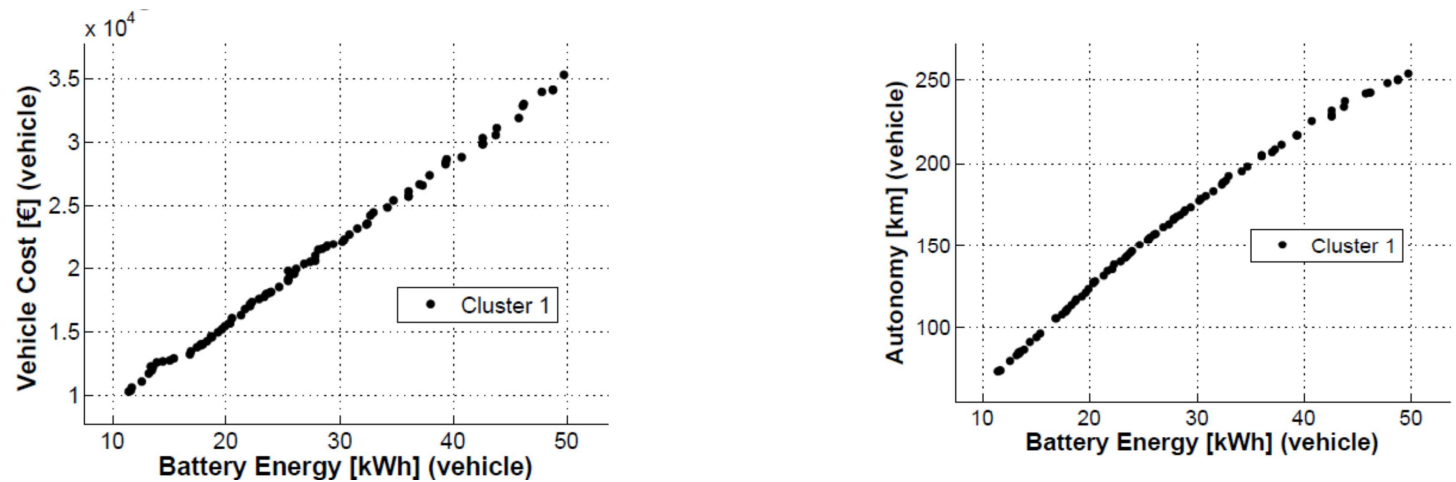

Figure A.1: correlations between a) cost and battery energy capacity and b) autonomy and battery energy capacity

\section{Appendix B:}

cost_powertrain $=$ cost_battery + cost $\_(\text {elmachine })+$ cost $\_(\text {thengine })[€]$

cost_car_shell $=17.3 * \operatorname{mass}[\mathrm{kg}]-3905.4[€]$

cost_operating $=$ cost_(electricity) $*$ electric_consumption $* \frac{150000}{100}[€]$

investment_cost $=$ cost_powertrain + cost_shell + cost_(CO2 emissions $),[€]$

total cost_mobility $=$ cost_(customer investment $)+$ cost_operating $[€]$ 
Table B.1: CO2 emissions cost, environmental cost, supported by the French government for 2013 [18]

\begin{tabular}{|c|c|}
\hline Emissions $\left[\mathrm{CO}_{2}(\mathrm{~g}) / \mathrm{km}\right]$ & (+)Bonus / (-) Malus [€] \\
\hline$\leq 20$ & $+7,000[€]$ \\
\hline$>20$ and $\leq 50$ & $+5,000[€]$ \\
\hline$>50$ and $\leq 60$ & $+4,500[€]$ \\
\hline 60 and $\leq 90$ & +550 [€] \\
\hline 700 ana $\leq 90$ & $+200[€]$ \\
\hline$\rangle 90$ and $\leq 105$ & $0[\theta]$ \\
\hline$>105$ and $\leq 135$ & -100[]$_{0}$ \\
\hline$>135$ and $\leq 140$ & $-400[€$ \\
\hline$>140$ and $\leq 145$ & \\
\hline$>145$ and $\leq 150$ & \\
\hline$>150$ and $\leq 155$ & $-1,000[€]$ \\
\hline$>155$ and $\leq 175$ & $-1,500[€]$ \\
\hline$>175$ and $\leq 180$ & $-2,000[€]$ \\
\hline$>180$ and $\leq 185$ & $-2,600[€]$ \\
\hline$\rangle 185$ and $\leq 190$ & $-3,000[€]$ \\
\hline$>190$ and $\leq 200$ & $-5,000[€]$ \\
\hline$>200$ and $\leq 230$ & $-6,000[€]$ \\
\hline$>230$ & $-6,000[€]$ \\
\hline
\end{tabular}

\section{Appendix C:}

Table C.1: CML01_short impact method and impact categories: [19]

\begin{tabular}{|c|c|c|}
\hline Category & Definition & Unit \\
\hline $\begin{array}{l}\text { acidification potential, } \\
\text { average European }\end{array}$ & $\mathrm{H} 2 \mathrm{CO} 3$ formation in oceans and on land by dissolving $\mathrm{CO} 2$ in water & kg SO2-eq \\
\hline $\begin{array}{l}\text { climate change, GWP } 100 \\
\text { years }\end{array}$ & $\begin{array}{l}\text { Significant and lasting change in the statistical distribution of weather } \\
\text { patterns over an extended period of time ( } 100 \text { years) }\end{array}$ & kg CO2-eq \\
\hline $\begin{array}{l}\text { eutrophication potential, } \\
\text { generic }\end{array}$ & $\begin{array}{l}\text { Environmental response to the addition of nitrates and phosphates. } \\
\text { (CML01) }\end{array}$ & \\
\hline & $\begin{array}{l}\text { - } \quad \text { Mass of algae, phytoplankton } \boldsymbol{\lambda} \\
\text { - } \quad \text { Biodiversity of fish species } \boldsymbol{y}\end{array}$ & kg PO4-eq \\
\hline $\begin{array}{l}\text { stratospheric ozone } \\
\text { depletion, ODP steady } \\
\text { state }\end{array}$ & & kg CFC-11-eq \\
\hline
\end{tabular}

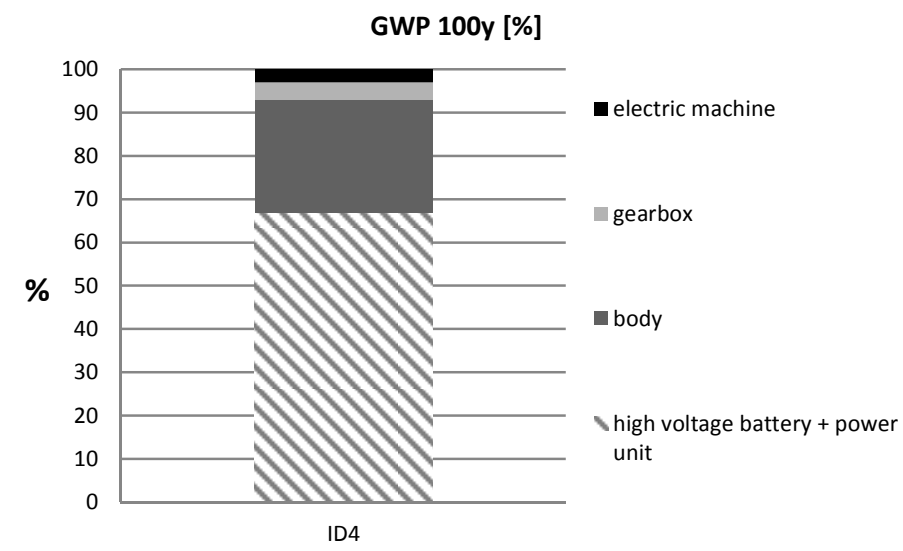

Figure C.1: powertrain components contributions for the production phase 


\section{References:}

[1] PSA Peugeot Citroën, Future standards for $\mathrm{CO} 2$ emissions, unpublished internal document, 2014.

[2] Spricher U, Analysis of the efficiency of future powertrains for individual mobility, MTZ, vol. 73, 2012.

[3] Guzzella L, Sciarretta A, Vehicle propulsion systems: introduction to modelling and optimization, third edition, pages: 108-109, Berlin: Springer; 2013.

[4] Ebbesen S, Elbert P, and Guzzella L, Engine downsizing and electric hybridization underconsideration of cost and drivability. Oil \& Gas Science and Technology-Revue d' IFP Energies nouvelles, vol. 68, issue 1, pages:109-116, 2012.

[5] Molyneaux A, A particular evolutionary method for the multi- objective optimization of complex integrated energy system including vehicle drivetrain, Ph. D. thesis, Ecole Polytechnique Fédérale de Lausanne, 2002.

[6] Leyland G, Multi- Objective Optimization applied to industrial energy problems, $\mathrm{Ph}$. D. thesis, Ecole Polytechnique Fédérale de Lausanne, 2002.

[7] ISO Environmental management - life cycle assessment principles and framework. International Standard, ISO 14'040; 2006.

[8] Warburg N, Forell A, et al. - Elaboration selon les principes des ACV des bilans énergétiques, des émissions de gaz à effet de serre et des autres impacts environnementaux induits par l'ensemble des filières de véhicules électriques et de véhicules thermiques, VP de segment B (citadines polyvalentes et VUL à l'horizon 2011 et 2020 - étude réalisée pour le compte de l'ADEME), www2.ademe.fr/servlet/getDoc?sort=$1 \& \mathrm{cid}=96 \& \mathrm{~m}=3 \& \mathrm{id}=90511 \& \mathrm{ref}=\&$ nocache $=$ yes $\& \mathrm{p} 1=111$, accessed on 18.05 .2014

[11] Gerber L, Maréchal F, Environomic optimal configurations of geothermal energy conversion systems: Application to the future construction of Enhanced Geothermal Systems in Switzerland, Energy, vol. 45, issue 1, 908-923, 2012

[12] Gerber L, Gassner M, Maréchal F, Systematic integration of LCA in process systems design: Application to combined fuel and electricity production from lignocellulosic biomass, Computers \& Chemical Engineering, vol. 35, issue 7, 1265-1280, 2011.

[13] Gerber L, Fazlollahi S, Maréchal F, A systematic methodology for the environomic design and synthesis of energy systems combining process integration, Life Cycle Assessment and industrial ecology, Computers \& Chemical Engineering vol. 59, 2-16, 2013.

[14] Steubing B, Ballmerb I, Identifying environmentally and economically optimal bioenergy plant sizes and locations: A spatial model of wood-based SNG value chains, Renewable Energy vol. 61, 57-68, 2014.

[15]Weber C, Multi-objective design and optimization of district energy systems including polygeneration energy conversion technologies, Ph.D. thesis, Ecole Polytechnique Fédérale de Lausanne, 2008.

[16] Fazlollahi S, Maréchal F, Multi-objective, multi-period optimization of biomass conversion technologies using evolutionary algorithms and mixed integer linear programming (MILP), Applied Thermal Engineering vol.50 1504-1513, 2013.

[17] S. Richet, P. Tonnelier, S. Martin, projet ENVironnement. L'Analyse de cycle de vie (LCA) - démarche et applications chez PSA, PSA Peugeot Citroën, unpublished internal report, 2012.

[18] French Government, 2013, Statistiques de développement durable, www.statistiques.developpement-durable.gouv.fr/energie-climat/s/prix-energies.html, accessed on 18.09.2013.

[19] Dubuis M, Tock L, Gerber L, Introduction to LENI Software - OSMOSE manual September 2009, EPFL, Switzerland, http://leniwiki.epfl.ch/index.php/OSMOSE, accessed on 20.05 .14 . 